\title{
Fungi in Porites lutea: association with healthy and diseased corals
}

\author{
J. Ravindran, Chandralata Raghukumar*, Seshagiri Raghukumar
}

National Institute of Oceanography, Dona Paula, Goa 403 004, India

\begin{abstract}
Healthy and diseased scleractinian corals have been reported to harbour fungi. However, the species of fungi occurring in them and their prevalence in terms of biomass have not been determined and their role in coral diseases is not clear. We have found fungi to occur regularly in healthy, partially dead, bleached and pink-line syndrome (PLS)-affected scleractinian coral, Porites lutea, in the reefs of Lakshadweep Islands in the Arabian Sea. Mostly terrestrial species of fungi were isolated in culture from these corals. Hyaline and dark, non-sporulating fungi were the most dominant forms. Fungal hyphae extended up to $3 \mathrm{~cm}$ within the corals. Immunofluorescence detection using polyclonal immunological probes for a dark, initially non-sporulating isolate (isolate \# 98-N28) and for a hyaline, non-sporulating fungus (isolate \# 98-N18) revealed high frequencies of these in PLS-affected, dead and healthy colonies of $P$. lutea. Total fungal biomass accounted for 0.04 to $0.05 \%$ of the weight of corals in bleached corals and was higher than in PLS-affected and healthy colonies. Scanning electron microscopy revealed the presence of fungi within the carbonate skeleton and around polyps. Fungi appear to be a regular component of healthy, partially dead and diseased coral skeleton.
\end{abstract}

KEY WORDS: Scleractinian coral $\cdot$ Porites lutea $\cdot$ Bleaching $\cdot$ Pink-line syndrome $\cdot$ Fungi $\cdot$ Immunofluorescence probe $\cdot$ Lakshadweep Islands $\cdot$ Arabian sea $\cdot$ India

Resale or republication not permitted without written consent of the publisher

\section{INTRODUCTION}

Several publications document the occurrence of fungi in healthy and diseased corals (Ramos-Flores 1983, Le Campion-Alsumard et al. 1995a, Smith et al. 1996). Kendrick et al. (1982) isolated terrestrial species of fungi in culture from a number of species of live corals and Le Campion-Alsumard et al. (1995a) suggested a symbiotic role for fungi in healthy corals. Raghukumar \& Raghukumar (1991) found them in necrotic patches of a massive coral. A number of new fungi have been described from dead corals (Kohlmeyer \& Volkmann-Kohlmeyer 1987).

Because of widespread mortality of coral reefs, documenting coral diseases has assumed importance in

${ }^{*}$ Corresponding author. E-mail: lata@csnio.ren.nic.in recent years and the spread of several old and new diseases has been reported from various parts of the world (Kushmaro et al. 1996, Goreau et al. 1997, 1998, Richardson 1998). Pathogenic organisms are identified for some of these, whereas for others the causal organisms are not yet known. Fungi are well known as plant and animal pathogens on land, and several fungal diseases have also been reported from the marine environment (Raghukumar 1996, Richardson 1998). A terrestrial species of fungus has also been shown to cause a disease in soft corals (Smith et al. 1996). In view of these reports, it is of interest to examine whether fungi associated with diseased corals are primary pathogens. We investigated the presence of fungi, and their species composition, prevalence and biomass in healthy, partially dead, bleached and pink-line syndrome (PLS)-affected scleractinian coral Porites lutea. 


\section{MATERIALS AND METHODS}

Study area. Diseases of corals were surveyed in the lagoon and intertidal zones of Kavaratti Island of the Lakshadweep archipelago off the south-west coast of India. The Lakshadweep archipelago comprises 36 islands with 12 atolls and lies between $10-12^{\circ} \mathrm{N}$ and $71^{\circ} 40^{\prime}-74^{\circ} \mathrm{E}$ in the Arabian Sea (Fig. 1) and forms the northern part of the Laccadive-Chagos Ridge. Samples of Porites lutea were collected in the lagoon at a depth of 3 to $5 \mathrm{~m}$ and samples of $P$. compressa were collected from the intertidal zone of reef flat in Kavaratti Island. Bleached and PLS-affected corals were collected in October and November 1998 and April 1999.

Frequency of fungi isolated from corals. Small pieces from the surface of healthy-looking colonies of Porites lutea and those showing PLS were chiselled and collected in sterile plastic bags under water. The samples were taken in ice and processed within $2 \mathrm{~h}$ of collection. The coral samples were broken further into smaller pieces inside the same plastic bags, thereby avoiding exposure of the broken surface to air to avoid contamination by aerial opportunistic fungi. The broken pieces ranging in size from 3 to $5 \mathrm{~mm}^{3}$ were directly plated on 1:5 diluted corn meal agar medium (HI-MEDIA, Mumbai, India) prepared with halfstrength sea water and fortified with streptomycin (0.5 $\mathrm{g} \mathrm{l}^{-1}$ medium) and penicillin (100000 $\mathrm{U} \mathrm{l}^{-1}$ medium) to inhibit bacterial growth. The presence of aerial fungi in the experimental site was tested by exposing 3 to 5 Petri plates containing corn meal agar medium to the air for $10 \mathrm{~s}$ during the isolation procedure. Subsequent comparison of these plates with experimental plates facilitated the detection of aerial contamination in isolation plates. Fungal hyphae emerging from coral pieces after 5 to $7 \mathrm{~d}$ of incubation in the dark were identified up to generic level. Frequency of fungi isolated from corals is expressed as a percentage.

Estimation of biomass of fungi. Coral samples from the polyp zone (up to $5 \mathrm{~mm}$ below surface) were weighed and decalcified in a decalcification solution (1:1 ratio of $20 \%$ citric acid $50 \%$ formic acid). The resulting material was homogenised in a VirTis homogeniser (VirTis Co., Gardiner, NY, USA) at $5000 \mathrm{rpm}$ for $15 \mathrm{~s}$ and filtered over a $0.22 \mu \mathrm{m}$ pore size Nuclepore polycarbonate filter paper under vacuum. The filter paper was stained with $0.01 \%$ Calcofluor, an optical brightener that stains chitin and cellulose (Sigma, St Louis, MO, USA) for 5 to $10 \mathrm{~s}$ (Mueller \& Sengbusch 1983). After the excess stain was washed with distilled water, the filter was mounted with a drop of non-fluorescent immersion oil and a cover slip was applied. The slides were stored in the dark at $5^{\circ} \mathrm{C}$ until further examination.

The slides were observed under an epifluorescence microscope with a blue excitation filter (Olympus BX60 , Tokyo, Japan). The images of fungal hyphae were captured with a charge-coupled device camera (Optronics Engineering, Goleta, CA, USA) and digitised using a frame-grabber card (Oculus TCX, Coreco Inc., Quebec, Canada). Since some coral detritus also showed fluorescence, images were manually traced in conjunction with Optimas 6.0 image analysis software (Optimas Corporation, Bothell, WA, USA) calibrated to the particular objective. Total length and average width of the mycelia for the total area were estimated using the software to calculate fungal biovolume. Mycelial fungal biomass was determined by assuming a mass density of $0.2 \mathrm{~g} \mathrm{~cm}^{-3}$ (Newell et al. 1986) and expressed as mg fungal biomass $\mathrm{g}^{-1}$ wet weight of

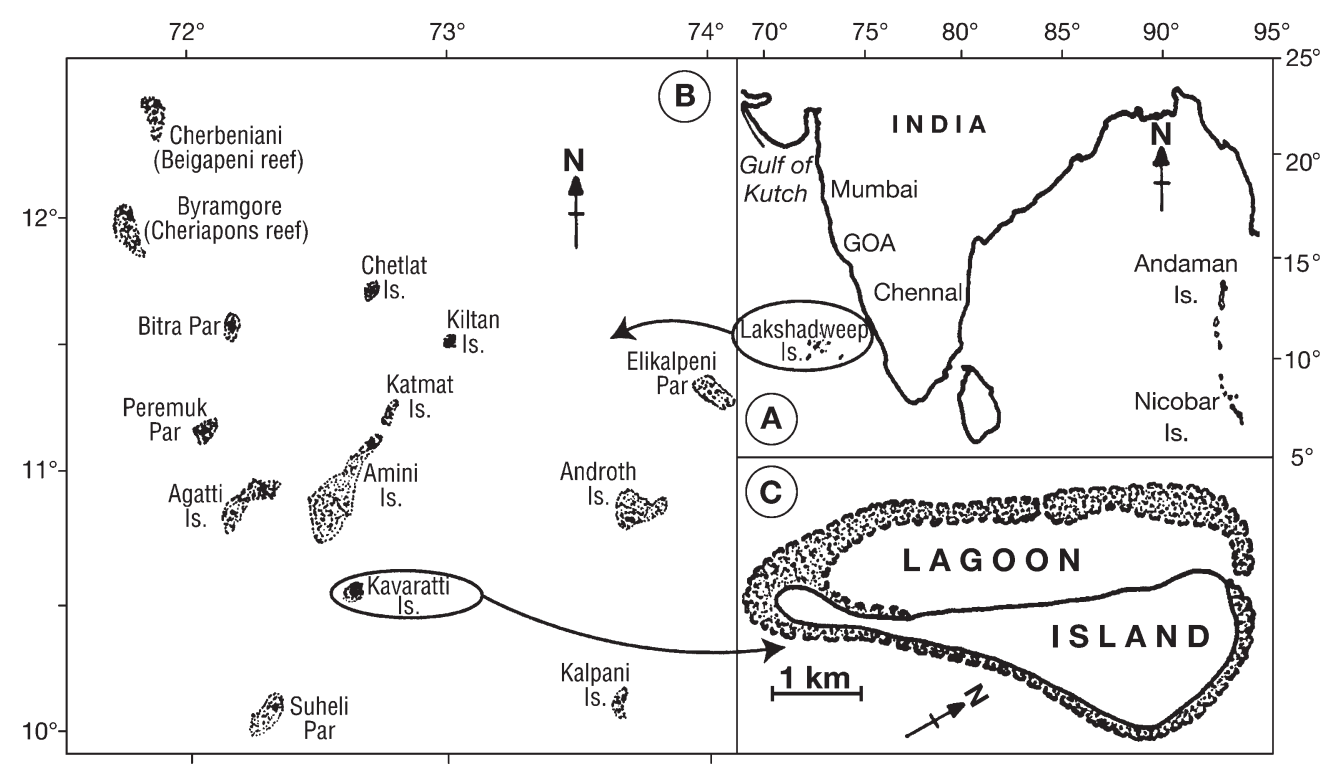

Fig. 1. Site of sampling: (A) Lakshadweep islands situated on the south-west of India in the Arabian Sea; (B) the group of islands of the Lakshadweep archipelago; (C) Kavaratti island with lagoon and a reef enclosing lagoon and island 
coral tissue. About 3 to 10 coral pieces were examined as replicates for this study.

Vertical distribution of fungi in corals. PLS-affected coral, the dead portion from partially dead corals and healthy-looking colonies of Porites lutea were cut into $1 \mathrm{~cm}$ thick sections with an electric rock cutting saw. These sections were washed with a jet of water to remove free particles and stained with $0.01 \%$ Calcofluor solution for 2 to $3 \mathrm{~min}$. After excess stain was washed off, the sections were examined under an epifluorescence microscope, using a blue excitation filter for the presence of fungi. Dark, non-sporulating (DNS) fungi did not stain with Calcofluor but could nonetheless be detected directly. The results are qualitatively expressed as presence or absence of fungi at various depths in the coral sections.

Scanning electron microscopy of corals. Healthylooking pieces of Porites lutea and those showing PLS collected from a 1 to $3 \mathrm{~m}$ depth in the lagoon were fixed immediately with $3 \%$ formalin prepared with sea water for $24 \mathrm{~h}$. They were further fixed with a $10 \%$ formalin solution for $48 \mathrm{~h}$. The fixed samples were rinsed thrice with tap water and were preserved in $70 \%$ ethanol and stored till use. Fixed samples were later decalcified (see above) and washed twice in distilled water and dehydrated in a graded acetone series. The tissues were dried critically using liquid $\mathrm{CO}_{2}$ in a critical point freeze drying apparatus (Structure Probe Inc., West Chester, PA, USA). The whole specimens (containing tissue and skeleton) were prepared in a similar manner without the decalcification step for scanning electron microscopic (SEM) studies. Critically dried specimens were sputter coated with gold-palladium and examined under an SEM to observe the fungi (model 5800 LV, JEOL, Akishima, Japan).

Immunofluorescence detection of selected fungi in Porites lutea. Antibodies were raised commercially (Genei India Pvt. Ltd, Bangalore, India) for 2 of the most frequently isolated fungi, a dark mycelial fungus (isolate \# 98 N-28, Curvularia lunata (Wakker) Boedijn) and a hyaline, non-sporulating (HNS), unidentified isolate (Isolate \# $98 \mathrm{~N}-18$ ) obtained from a partially dead and a PLS-affected coral, respectively. About $2 \mathrm{mg}$ of fungal pellet was crushed in $2 \mathrm{ml} 0.15 \mathrm{M} \mathrm{NaCl}$ and centrifuged, and $1 \mathrm{ml}$ supernatant was emulsified with $1 \mathrm{ml}$ Freund's adjuvant. This was injected subcutaneously at multiple sites on the back of New Zealand male white rabbits (2 rabbits for each fungus). The first booster injection was given after 6 wk of the primary injection and the second booster was given after a further 4 wk. The antibody titre was monitored by Dot ELISA after $10 \mathrm{~d}$ of the booster injection and yielded a titre value of 1:2000 for isolate \# 98 N-18 and 1:5000 for isolate \# $98 \mathrm{~N}-28$. The antibodies thus obtained were diluted 4 times in phosphate buffered saline (PBS) con- taining $8.0 \mathrm{~g} \mathrm{NaCl}, 0.2 \mathrm{~g} \mathrm{KCl}, 0.2 \mathrm{~g} \mathrm{KH}_{2} \mathrm{PO}_{4}$ and $1.15 \mathrm{~g}$ $\mathrm{Na}_{2} \mathrm{HPO}_{4}$ in $1000 \mathrm{ml}$ distilled water (Mendoza et al. 1995). The coral specimens were crushed into a coarse powder and incubated with $50 \mu$ l of the diluted antibody solution in an Eppendorf tube for $1 \mathrm{~h}$ at $25^{\circ} \mathrm{C}$. The mixture was vortexed after dilution to $1000 \mu \mathrm{l}$ with PBS solution. The slurry was centrifuged at $4000 \mathrm{rpm}$ for $1 \mathrm{~min}$. After the supernatant was decanted, the coral debris was similarly washed 3 times with $1000 \mu \mathrm{l}$ of PBS. The samples were incubated in $50 \mu \mathrm{l}$ of the secondary antibody (Genei India Pvt. Ltd), and the goat anti-rabbit anti-serum was tagged with fluroscein isothiocyanate for $1 \mathrm{~h}$ at $25^{\circ} \mathrm{C}$. The excess stain was washed with PBS as described. The coral debris was transferred onto a slide and viewed under blue excitation (excitation wave length 400 to $440 \mathrm{~nm}$ and barrier filter \# 475) for the presence of fungi and photographed. Specificity of the antiserum was confirmed by the absence of immunofluorescence staining by 4 species of Aspergillus, Cladosporium sp. and mycelial yeast isolated from $P$. lutea. Staining of coral sections with preimmune sera did not show any immunofluorescence.

Histology. To detect fungi within polyps, coral polyps were removed from formalin fixed coral pieces following decalcification as described above. The polyps were dehydrated in a graded series of ethanol and embedded in wax and sectioned. The sections were stained with basic fuchsin (Bancroft 1995).

\section{RESULTS}

Bleached corals were collected 5 mo after the major coral reef bleaching event reported from all over the world including the Andamans in the Bay of Bengal (Ravindran et al. 1999). Line transect observations carried out in October 1998 and April 1999 in the lagoon at Kavaratti Island revealed the presence of bleaching and PLS in Porites lutea colonies. In the PLS-affected corals, the coral tissue around the dead patch appeared bright pink in otherwise pale brown morphotypes of P. lutea (Fig. 2).

Several fungi from PLS-affected corals as well as from dead, bleached and healthy ones were isolated from the surface of the coral up to $5 \mathrm{~mm}$ depth (Table 1). The highest frequency of fungi occurred in dead patches. There were no differences in the frequencies of fungi occurring in healthy and PLS-affected colonies of Porites lutea. Most of the identified species of fungi belonged to terrestrial genera. DNS and HNS forms were the most dominant in all the healthy-looking and stressed corals (Table 1). One of the DNS strains, \# 98 N-28, isolated from a dead patch during 1998 sporulated in subsequent culture, although poorly, and was identified as Curvularia lunata (Wakker) Boedijin. The 

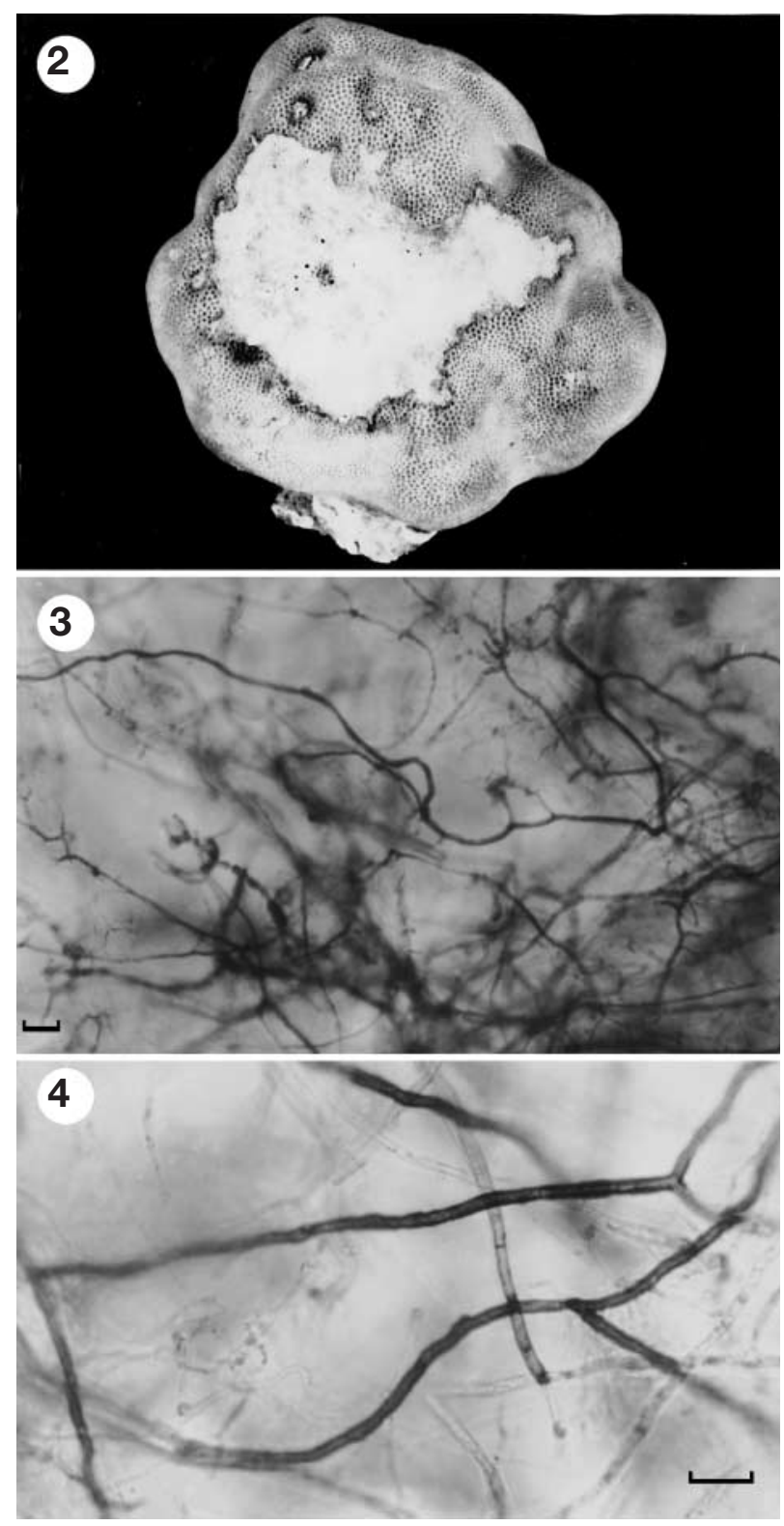

Figs 2 to 4 . Pink-line syndrome in a Porites lutea colony in the lagoon of Kavaratti. Fig. 3. Fungal hyphae and algal filaments from the polyp zone, visible after decalcification of the surface layer. Scale bar $=20 \mu \mathrm{m}$. Fig. 4. Septate hyphae of a dark, non-sporulating fungus seen after decalcification of the surface layer. Scale bar $=20 \mu \mathrm{m}$

other dominant and frequently isolated fungi from these corals were various species of Aspergillus, a species of Cladosporium and a mycelial yeast. On decalcification of the top $5 \mathrm{~mm}$ layer, black septate fungal mycelia interspersed with thin hyaline fungal mycelia, and cyanobacterial and algal filaments were observed (Figs 3 \& 4).

Fungi were isolated from almost all healthy as well as PLS-affected colonies of Porites compressa from the intertidal zone. Here too the HNS (about 30\% frequency) and DNS fungi (about 60\% frequency) were isolated.

Sections of corals stained with Calcofluor revealed the presence of fungi as bright blue septate filaments under the epifluorescence microscope in contrast to bright orange cyanobacteria or red chlorophycean algal filaments. The highest fungal biomass occurred in bleached corals collected in October and November 1998, nearly 5 mo after the major bleaching event, whereas the fungal biomass was lower in corals with dead necrotic patches and very negligible in PLSaffected corals (Fig. 5). Examination of the depth-wise distribution of the hyaline and dematiaceous fungi revealed that they pervaded the PLS-affected corals and necrotised patches of partially dead corals more frequently than the healthy ones (Fig. 6).

An isolate of HNS fungi (\# $98 \mathrm{~N}-18$ ) as well as Curvularia lunata (\# $98 \mathrm{~N}-28$ ) were detected in corals by the immunofluorescence probes (Figs $7 \& 8$ ). Branched mycelia of both the fungi adhered closely to calcium carbonate particles and often appeared to be present within the carbonate skeleton (Figs 7 \& 8). Frequencies of Curvularia lunata (isolate \# $98 \mathrm{~N}-28$ ) were similar in healthy, PLS-affected and dead corals (about $50 \%$ frequency). The HNS form (isolate \# $98 \mathrm{~N}-18$ ) was found to be more frequent in the healthy (60\% frequency) and partially dead corals (80\% frequency) than in PLSaffected corals with $50 \%$ frequency (Fig. 9).

SEM of the healthy, bleached and PLS-affected corals showed that fungi perforated the coral skeleton (Figs 10, 11 \& 12). The hyphae showed distinct swellings at regular intervals (Figs 10 \& 11). Fungal hyphae showed basal swellings on emergence from the carbonate skeleton (Figs 12 \& 13). Occasionally, we also observed 'conidia-like' structures within the coral skeleton (Fig. 14). Ramifying fungal hyphae emerged

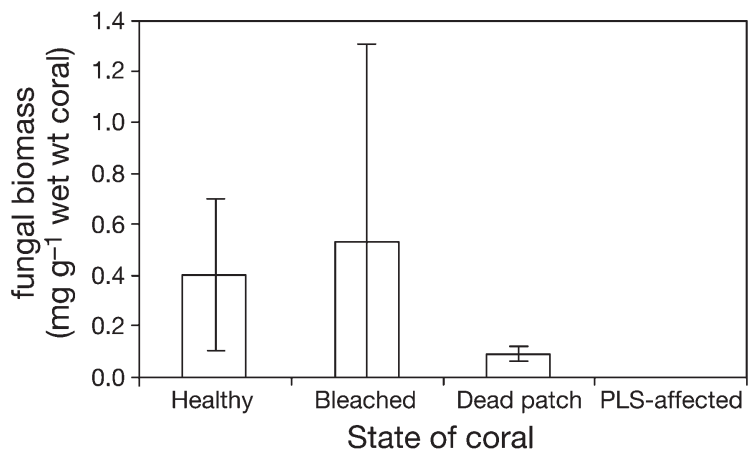

Fig. 5. Fungal biomass in $\mathrm{mg} \mathrm{g}^{-1}$ coral wet weight. Preweighed crushed corals were stained with the optical brightener Calcofluor stain and biovolume of fungi present was calculated using the Image analysis software. The fungal biovolume was converted to fungal biomass as described under 'Materials and methods' 
Table 1. Fungi isolated from the polyp zone of Porites lutea collected from the lagoon in Kavaratti, Lakshadweep Island. Dead patch: coral with necrotic patch; ND: no data; PLS: coral showing pink-line syndrome

\begin{tabular}{|lrrrrrr|}
\hline Fungal species & \multicolumn{7}{c|}{ Frequency of isolation (\%) } \\
& Healthy & PLS & Dead patch \\
& 1998 & 1999 & 1998 & 1999 & 1998 & 1999 \\
\hline Dark, non-sporulating forms & 22 & 0 & 0 & 25 & 60 & ND \\
Orange, non-sporulating forms & 6 & 0 & 0 & 0 & 0 & ND \\
Hyaline, non-sporulating forms & 0 & 36 & 25 & 0 & 7 & ND \\
Acremonium sp. & 0 & 0 & 0 & 0 & 13 & ND \\
Fusarium sp. & 11 & 0 & 0 & 0 & 0 & ND \\
Aspergillus sp. & 17 & 7 & 25 & 15 & 7 & ND \\
Cladosporium sp. & 0 & 7 & 8 & 5 & 0 & ND \\
Mycelial yeasts & 0 & 21 & 0 & 0 & 0 & ND \\
Labyrinthula sp. & 0 & 0 & 0 & 5 & 0 & ND \\
Unidentified & 0 & 0 & 0 & 5 & 0 & ND \\
Chaetomium sp. & 0 & 0 & 0 & 10 & 0 & ND \\
Aureobasidium sp. & 0 & 0 & 0 & 5 & 0 & ND \\
Total & 56 & 71 & 58 & 70 & 87 & ND \\
& & & & & & \\
\hline
\end{tabular}

from the coral skeleton and spread around the polyps (Figs $15,16 \& 17)$. The fungal hyphae were covered by remineralised carbonate precipitate (Figs 10, $13 \& 17$ ) and most often fresh accretion of amorphous repair carbonate around fungal hyphae was noticed (Figs $12 \& 13$ ). Whole polyps removed after careful decalcification of the surface layer of coral in the pink-line zone also revealed the presence of fungal hyphae around the periphery of polyps (Fig. 18). Sections of polyps from healthy and PLS-affected corals stained with basic fuchsin showed abundant fungal hyphae around the polyps (Fig. 19).

Fig. 6. Vertical sections of coral. Vertical distribution of fungi within healthy, pink-line syndrom-affected and partially dead corals. The horizontal bars represent fungal presence detected by Calcofluor staining (as described in 'Materials and methods') at a particular depth in coral. The dark bars represent detection of fungi in more than 2 transects in a vertical section of the coral. Numbers 1 to 4 represent replicate coral colonies examined

\section{DISCUSSION}

The scleractinian coral Porites lutea in 4 different stages of health were examined in this study. The first of these is corals affected by the pink line, a syndrome being reported for the first time (PLS). A similar syndrome was reported to occur in massive corals from Sri Lanka in 1998 (P. Weerakkody pers. comm.). It is possible that lowered host resistance due to stress-related factors induced the PLS. We are investigating the biochemical nature of the pink band observed in these corals. The pink band between the dead and healthy coral tissues may play a role in the coral's immunological and chemical defence systems similar to the pink band observed in the tissues of

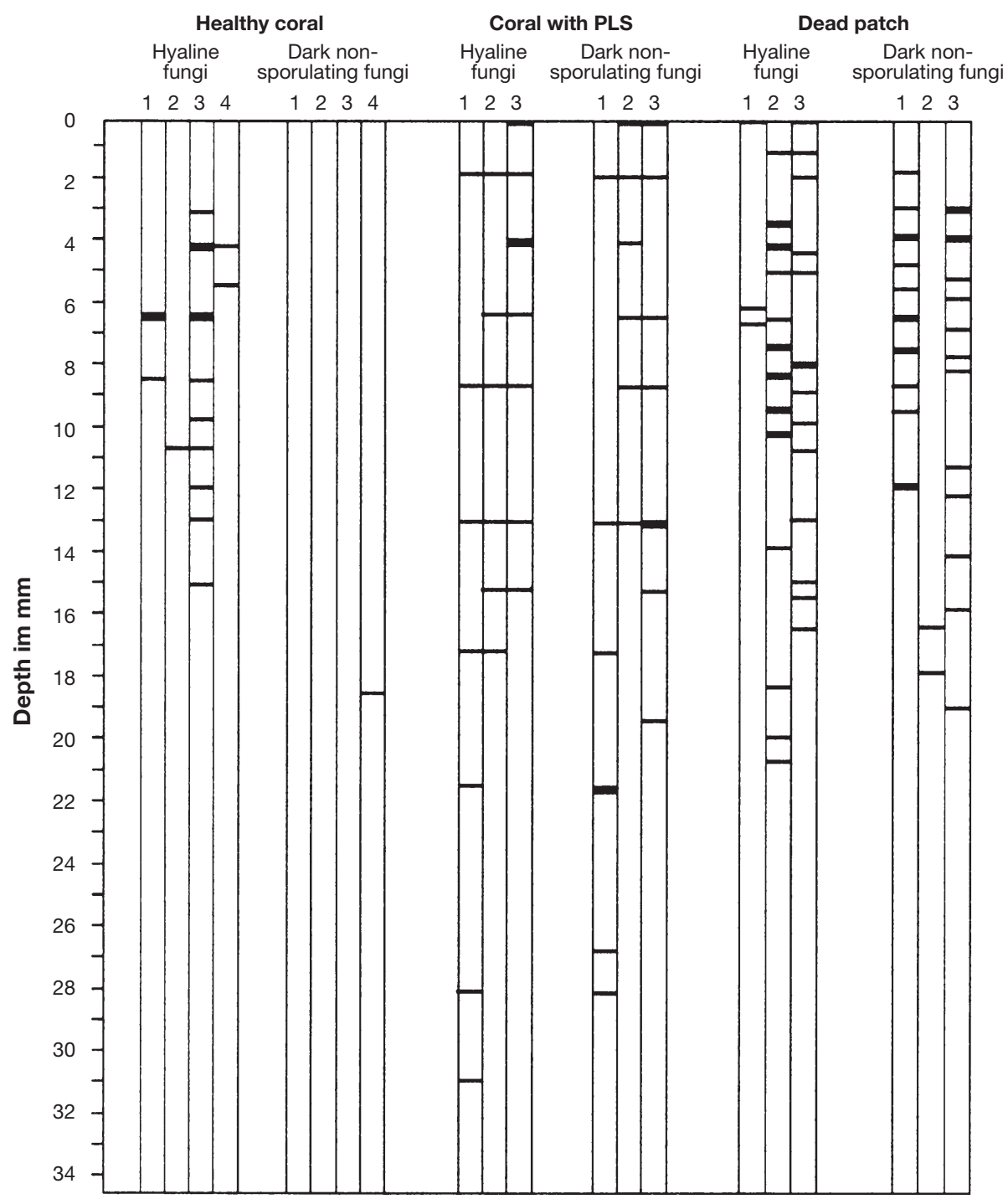



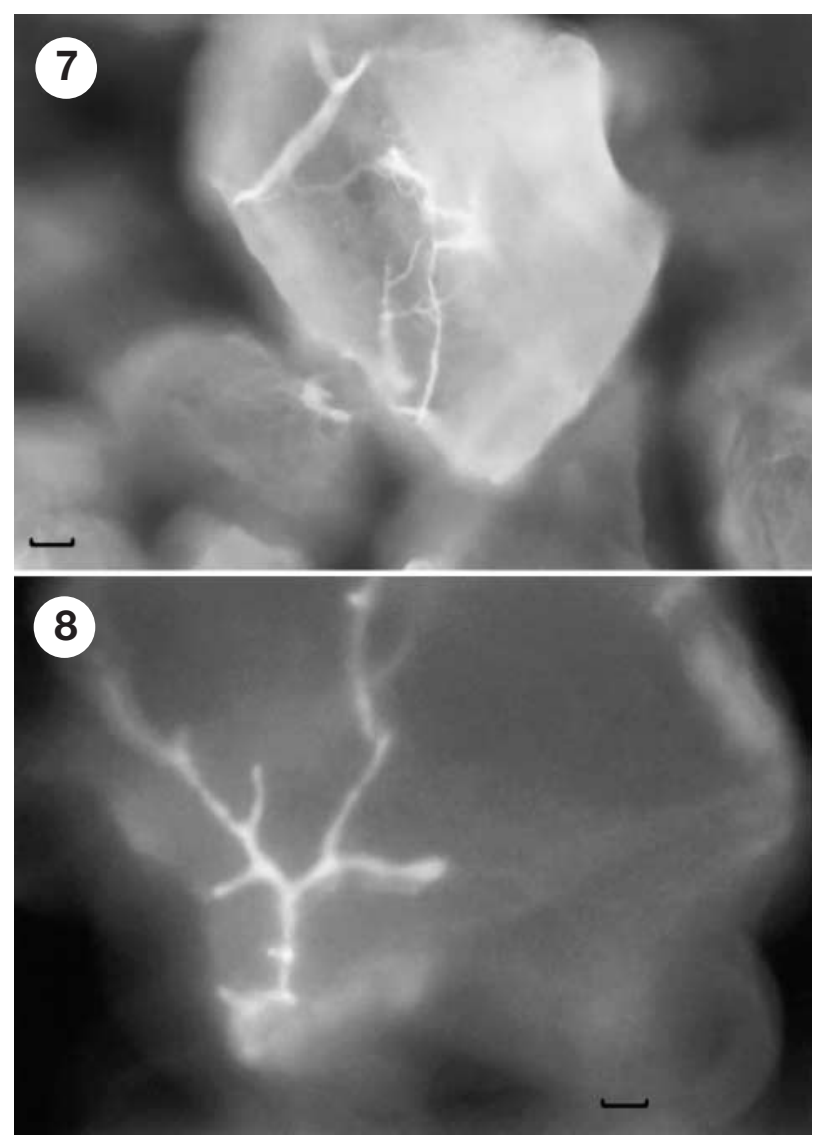

Fig. 7. Immunofluorescence detection of the hyaline, nonsporulating fungus strain $98 \mathrm{~N}-18$ inside coral. Scale bar = $20 \mu \mathrm{m}$. Fig. 8. Immunofluorescence detection of the dark, nonsporulating fungus strain $98 \mathrm{~N}-28$, Curvularia lunata, inside coral. Scale bar $=10 \mu \mathrm{m}$

pink colonies of Pocillopora damicornis at the contact sites between non-similar colonies (Dove et al. 1995). We also studied 'bleached' specimens of P. lutea. A coral-reef bleaching event is 1 of the examples of a response to environmental stress such as elevated temperature, salinity or illumination, excessive sedimentation, turbidity or chemical pollution (Williams \& Williams 1990). In addition to the above, we examined healthy-looking corals devoid of any symptoms of damage and disease, as well as necrotised and dead patches on 'partially dead corals' (Meesters et al. 1996).

Our studies show that fungi are a regular component of corals. The present study was carried out over a period of $2 \mathrm{yr}$ and fungi were seen to be constantly associated with healthy-looking, partially dead, bleached and PLS-affected corals. They were found extending to substantial depths within corals. Data presented show their distribution in corals up to a depth of only $3 \mathrm{~cm}$ but they were observed occasion-

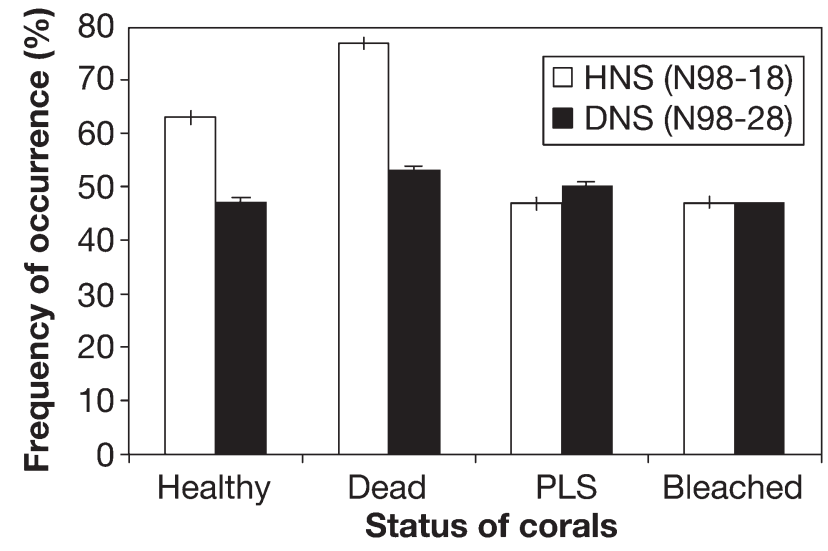

Fig. 9. Percentage frequency occurrence of the hyaline, nonsporulating (HNS) (strain $98 \mathrm{~N}-18$ ) and dark, non-sporulating (DNS) forms (Curvularia lunata, strain $98 \mathrm{~N}-28$ ) in healthy, dead and PLS-affected corals of Porites lutea, detected by immunofluorescence probes

ally at depths of nearly 7 to $8 \mathrm{~cm}$ and sometimes even deeper. No regular pattern of fungal distribution within corals was observed similar to the black banding seen in Porites lutea from Indonesian reefs (Bak \& Laane 1987). Black bands in sections of $P$. lutea and $P$. lobata skeletons in Mayotte Island in the Mozambique Channel and Moorea Island in French Polynesia were attributed to the secretion of organic dark pigments by fungi and their conidia (Priess et al. 2000). In our study, we observed a highly patchy distribution of fungal mycelia within the corals. This resulted in a high variability between replicates used for calculating the total biomass, culturable numbers and frequencies as observed by immunofluorescence. Fungal biomass constituted up to $0.05 \%$ of the weight of dead corals. This value is even higher than that reported by Raghukumar et al. (1995) for submerged detritus of leaves of the mangrove Rhizophora apiculata Blume $(0.015 \%$ of the detrital weight). Fungal biomass of 3 to $5 \mathrm{mg} \mathrm{cm}^{-3}$ has been reported in necrotic patches of corals from the Andaman Islands in the Bay of Bengal on the east coast of India (Raghukumar \& Raghukumar 1991). Fungi, therefore, are an apparently important component of corals.

Little is known of the diversity of fungi that inhabit corals. Certain 'obligate marine fungi' have been described from dead coral slabs (Kohlmeyer \& VolkmannKohlmeyer 1987) and the term 'facultative marine fungi' has been coined to accommodate the possibility of terrestrial species of fungi having adapted to the marine environment. Raghukumar \& Raghukumar $(1998,1999)$ hypothesised that terrestrial fungi are indeed active in the sea. Kendrick et al. (1982) have isolated species of Aspergillus, Cladosporium and Acremonium in culture from healthy Porites colonies in the Caribbean and the 

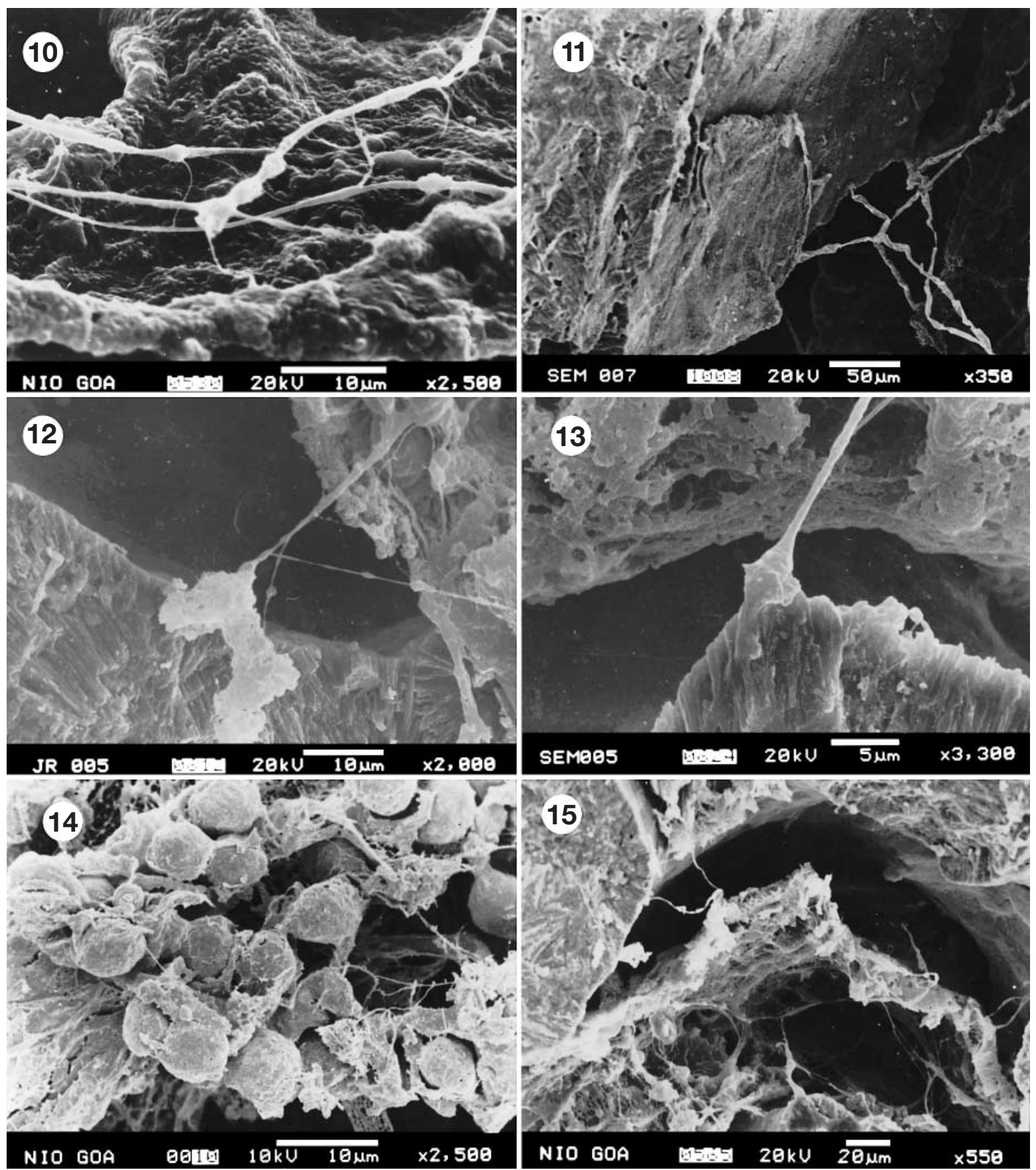

Figs 10 \& 11. Fungal hyphae with swellings ramifying within coral skeleton as observed under a scanning electron microscope Fig. 12. Deposition of amorphous repair carbonate around the invading fungal hypha. Fig. 13. A fungal hypha showing basal $\overline{\text { swelling }}$ at the site of emergence from the carbonate skeleton. Fig. 14. A group of 'conidia-like' structures. Fig 15. Fungal hyphae travelling between polyp and carbonate skeleton

South Pacific. Fungi have been isolated from bleached corals of Millipora complanta (Te Strake et al. 1988). In the present study, we consistently cultured terrestrial fungi from corals under different health conditions. In addition, we have established the presence of the common terrestrial fungus, Curvularia lunata (\# $98 \mathrm{~N}-28$ ), within healthy and PLS-affected corals using polyclonal antibodies. This fungus was labelled as a DNS form in our initial isolations. We isolated several other DNS forms in our study, although their identity is not known. However, it is possible that these too were terrestrial fungi, possibly belonging to Curvularia lunata. 

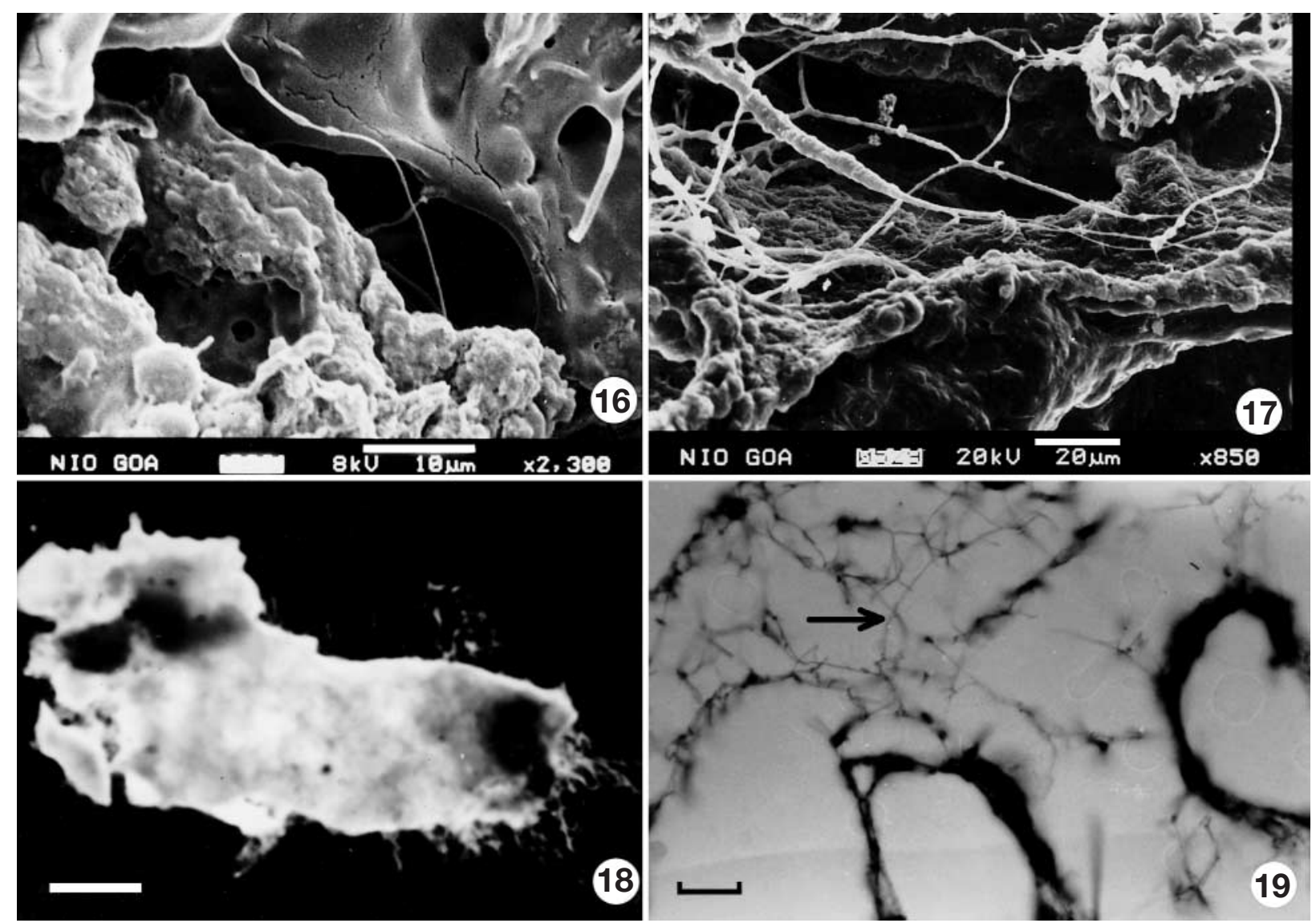

Figs 16 \& 17. Fungal hyphae travelling between polyp and carbonate skeleton. Fig. 18. Fungal hyphae around a polyp picked up from the pink line. Scale bar $=370 \mu \mathrm{m}$. Fig. 19. Fungal hyphae (arrow) seen around a polyp in a transverse section of pink-line syndrome-affected coral. Scale bar $=20 \mu \mathrm{m}$

This study reiterates the hypothesis of Raghukumar \& Raghukumar $(1998,1999)$ that terrestrial fungi are components of certain habitats in the sea. HNS forms were also frequent in our isolations. Immunofluorescence technique revealed the frequent presence of 1 of these isolates (\# $98 \mathrm{~N}-18$ ) within corals. The presence of such non-sporulating fungi has also been reported by Kendrick et al. (1982) in healthy corals. The terrestrial fungus Aspergillus sydowii causes rapid erosion and death of sea fan corals in the Caribbean (Smith et al. 1996). More recently, Shinn et al. (2000) reported the presence of terrestrial fungi, especially spores in the dust particles that are blown from Africa to the Caribbean, where they settle on the coral and trigger mass mortality in coral reef.

In view of the above, the behaviour and role of fungi within healthy and diseased corals merit detailed investigations. In this study, fungi were found within the calcium carbonate skeleton and around polyps. SEM studies showed entry of fungi from the coral carbonate skeleton into the polyps, the presence of amorphous 'repair carbonate' around the site of fungal penetration and precipitation of such 'repair carbonate' around the fungal hyphae. Le Campion-Alsumard et al. (1995a) explained this phenomenon of fungal growth and the polyp's defence mechanisms. During their process of penetration of coral skeleton, their role as bioeroding agents has been confirmed (Perkins \& Halsey 1971, Zeff \& Perkins 1979, Le Campion-Alsumard et al. 1995a,b). In molluscan shells with fungi, 3 times more calcium was leached than in control shells without fungi (Raghukumar et al. 1988). The high abundance and biomass of fungi that we observed in corals indicate their potential importance as bioeroders of calcium carbonate skeletons in the sea. While bioeroding activities of fungi in dead or diseased portions of corals are understandable, the possibility of such an activity in normal, healthy corals appears paradoxical.

Priess et al. (2000) observed formation and germination of a conidium inside the coral skeletons of Porites lutea. However, we rarely noticed this behaviour within corals. This observation, plus the fact that nonsporulating forms were common in corals suggests that these fungi might survive and propagate by means 
other than spore formation, such as hyphal fragments (Raghukumar \& Raghukumar 1999).

The possible pathogenic role of fungi associated with polyps in the pink-line zone of corals could not be unequivocally shown in the present study although dense fungal hyphae were found around polyps. Fungi as pathogenic organisms are described for Aspegillus sydowii in sea fans, causing mass mortalities (Smith et al. 1996). Association of an unidentified lower fungus with black-band disease in star corals (Ramos-Flores 1983) and necrotic patches in massive corals (Raghukumar \& Raghukumar 1991) has been reported, without proof of their pathogenicity. Further studies are required to examine the role of fungi in coral pathogenicity. One possibility is that normal residential fungal flora, and not necessarily extraneous invaders, may become opportunistic pathogens under climate variability and anthropogenic stress, as reported for mangrove disease, induced by cyanobacterial symbionts (Rützler 1988).

In conclusion, our study substantiates earlier studies on the presence of fungi in corals and shows that fungi are residential flora within corals. The constant presence and pervasive distribution of fungi, and a high biomass within the polyp zone confirm this. Fungi have been reported to be associated with micrite tubules of the Devonian era (Kobluk \& Risk 1974) and modern carbonate sediments (Perkins \& Halsey 1971, Perkins \& Tsentas 1976). Association of fungi with present-day corals need not be the effect of modern anthropogenic effects, but may be the effect of long-term evolutionary association.

Acknowledgements. A financial grant for this work came from the Department of Ocean Development (DOD) and the Ministry of Environment and Forests (MOEF) New Delhi. J.R. would like to thank DOD and CSIR for the research fellowship during the period of this study. Our sincere thanks to Dr Ismail Koya, Deputy Director of Science and Technology, Lakshadweep Islands, for allowing us to use the laboratory facilities at Kavaratti. This is NIO's contribution number 3710.

\section{LITERATURE CITED}

Bak RPM, Laane RWPM (1987) Annual black bands in skeletons of reef corals (Scleractinia). Mar Ecol Prog Ser 38: 169-175

Bancroft JD (1995) Histochemical techniques, 2nd edn, Butterworth, London

Dove SG, Takabayashi M, Hoegh-Guldberg O (1995) Isolation and partial characterization of the pink and blue pigments of Pocilloporid and Acroporid corals. Biol Bull 189: 288-297

Goreau TJ, Bruckner AW, Cervino J, Hayes RL and 7 others (1997) Assessing coral reef health. Science 277:165-166

Goreau TJ, Cervino J, Goreau M, Hayes RL and 14 others (1998) Rapid spread of disease in Caribbean coral reefs. Rev Biol Trop 46(Suppl 5):157-171

Kendrick B, Risk MJ, Michaelides J, Bergman K (1982)
Amphibious microborers: bioeroding fungi isolated from live corals. Bull Mar Sci 32:862-867

Kobluk DR, Risk MJ (1974) Devonian boring algae and fungi associated with micrite tubules. Can J Earth Sci 11: 1606-1610

Kohlmeyer J, Volkmann-Kohlmeyer B (1987) Koralionastetaceae fam. nov. (ascomycetes) from coral rock. Mycologia 79:764-778

Kushmaro A, Loya Y, Fine M, Rosenberg E (1996) Bacterial infection and coral bleaching. Nature 380:396

Le Campion-Alsumard T, Golubic S, Priess K (1995a) Fungi in corals: symbiosis or disease? Interaction between polyps and fungi causes pearl-like skeleton biomineralization. Mar Ecol Prog Ser 117:137-147

Le Campion-Alsumard T, Golubic S, Hutchings P (1995b) Microbial endoliths in skeletons of live and dead corals: Porites lobata (Moorea, French Polynesia). Mar Ecol Prog Ser 117:149-157

Meesters EH, Wesseling I, Bak RPM (1996) Partial mortality in three species of reef-building corals and the relation with colony morphology. Bull Mar Sci 58:838-852

Mendoza H, Lòpez-Rodas V, González-Gil S, Aguuilera A, Costas E (1995) The use of polyclonal antisera and blocking of antibodies in the colonization of marine dinoflagellates: species-specific and clone-specific antisera against Gymnodium and Alexandrium. J Exp Mar Biol Ecol 186: 103-115

Mueller V, Sengbusch PV (1983) Visualization of aquatic fungi (Chytridiales) parasitising on algae by means of induced fluorescence. Arch Hydrobiol 97:471-485

Newell SY, Fallon RD, Miller JD (1986) Measuring fungal biomass dynamics in standing dead leaves of a salt marsh vascular plant. In: Moss ST (ed) The biology of marine fungi. Cambridge University Press, Cambridge, p 19-25

Perkins RD, Halsey SD (1971) Geologic significance of microboring fungi and algae in Carolina shelf sediments. J Sediment Petrol 41:843-853

Perkins RD, Tsentas CI (1976) Microbial infestation of carbonate substrates planted on the St Croix shelf, West Indies. Bull Geol Soc Am 87:1615-1628

Priess K, Le Campion-Alsumard L, Golubic S, Gadel F, Thomassin BA (2000) Fungi in corals: black bands and density-banding of Porites lutea and P. lobata skeleton. Mar Biol 136:19-27

Raghukumar C (1996) Zoosporic fungal parasites of marine biota. In: Dayal R (ed) Advances in zoosporic fungi. M.D. Publ. Pvt. Ltd, New Delhi, p 61-83

Raghukumar C, Raghukumar S (1991) Fungal invasion of massive corals. PSZN I: Mar Ecol 12:251-260

Raghukumar C, Raghukumar S (1998) Barotolerance of fungi isolated from deep-sea sediments of the Indian Ocean. Aquat Microb Ecol 15:153-163

Raghukumar S, Raghukumar C (1999) Marine fungi: a critique. Aquat Microb Newslett 38:26-27

Raghukumar C, Raghukumar S, Sharma S, Chandramohan D (1988) Endolithic fungi from deep-sea calcareous substrata: isolation and laboratory studies. In: Thompson $\mathrm{M}_{\text {, }}$ Sarojini R, Nagabhushanam R (eds) Marine biodeterioration. Oxford IBH Publ, New Delhi, p 693-702

Raghukumar S, Sathe-Pathak V, Sharma S, Raghukumar C (1995) Thraustochytrid and fungal component of marine detritus. III. Field studies on decomposition of leaves of the mangrove Rhizophora apiculata. Aquat Microb Ecol 9: $117-125$

Ramos-Flores T (1983) Lower marine fungus associated with black line disease in star corals (Montastrea annularis E. \& S.). Biol Bull 165:429-435 
Ravindran J, Raghukumar C, Raghukumar S (1999) Disease and stress-related mortality of corals in Indian reefs and observations on bleaching of corals in the Andamans. Curr Sci 76:233-237

Richardson LL (1 998) Coral diseases: what is really known? Trends Ecol Evol 13:438-443

Rützler K (1988) Mangrove sponge disease induced by cyanobacterial symbionts: failure of a primitive immune system? Dis Aquat Org 5:143-149

Shinn EA, Smith GA, Prospero JM, Betzer P, Hayes ML, Garrison V, Barber RT (2000) African dust and the demise of

Editorial responsibility: David Bruno,

Aberdeen, Scotland, UK
Caribbean coral reefs. Geophys Res Lett 27:3029-3032

Smith GW, Ives LD, Nagelkerken IA, Ritchie KB (1996) Caribbean sea-fan mortalities. Nature 383:487

Te Strake D, Jaap C, Truby E, Reese R (1988) Fungal elements in Millipora complanta Lamarck, 1816 (Cnidaria: Hydrozoa) after mass expulsion of zooxanthellae. Fla Sci 51:184-188

Williams EH, Williams LB Jr (1990) The world-wide coral reef bleaching cycle and related sources of coral mortality. Atoll Res Bull 335:1-71

Zeff ML, Perkins RD (1979) Microbial alteration of Bahamian deep-sea carbonates. Sedimentology 26:175-201

Submitted: October 24, 2000; Accepted: April 6, 2001

Proofs received from author(s): November 16, 2001 